\title{
PENGEMBANGAN PROTATIK (PROGRAM TABEL FONETIK) BERBASIS WEBSITE SEBAGAI MEDIA PEMBELAJARAN PRONUNCIATION PRACTICE
}

\author{
Ayu Bandu Retnomurti and RR Astri Indriana Octavita
}

English Education Department, Indraprasta PGRI University, Jakarta

\begin{abstract}
This research aims to develop manual modules into a versatile technology web-based module in Phonetic Table Program PROTATIK webbased and to explain the interest and the influence of the media in Pronunciation Practice class FBS Indraprasta PGRI University Jakarta. Verbal-based learning such as English pronunciation practice requires the existence of an effective media because if it is directly given without media, inaccuracies in pronunciation, spelling, repetition will occur. The research belongs to Research and Development that includes conducting of a preliminary study to examine the theory and supervise the product, developing and testing or validating a new product. Whereas the development requires an analysis, develops syllabus and materials, creates and revises media. As conducting the try out in the end of the lesson, students are required to give comments on PROTATIK concerning the advantages, disadvantages, suggestions for improvement the media. PROTATIK provides pronunciation models for students to practice and help them to understand the sound of English as it is equipped with buttons to practice presented by nonnative speakers.
\end{abstract}

Keywords: Development, Learning media Web-based PROTATIK, Pronunciation Practice, Undergraduate Student.

\begin{abstract}
Abstrak: Tujuan penelitian ini adalah mengembangkan modul manual menjadi modul berbasis teknologi tepat guna mutakhir berupa PROTATIK (program tabel fonetik) sebagai media berbasis website dan menjelaskan daya tarik dan dampak media tersebut di kelas Pronunciation Practice Jurusan Pendidikan Bahasa Inggris, FBS Universitas Indraprasta PGRI Jakarta. Pembelajaran yang bersifat verbal seperti praktik pelafalan Bahasa Inggris memerlukan adanya media yang efektif karena apabila secara langsung diberikan tanpa media akan terjadi ketidakakuratan dalam pelafalan, pengejaan, dan pengulangan. Jenis penelitian termasuk ke dalam Penelitian dan Pengembangan berisi studi pendahuluan dilakukan Pada tahap uji coba di akhir pembelajaran kelas Pronunciation Practice, mahasiswa diminta memberikan komentar meliputi kelebihan, kekurangan dan saran perbaikannya. PROTATIK berisi model pengucapan untuk praktik siswa yang digunakan untuk membantu proses komunikasi sehingga menarik minat mahasiswa dalam memahami materi bunyi bahasa Inggris yang dilengkapi tombol ikon dan suara nonpenutur asli.
\end{abstract}

Kata Kunci: Pengembangan, Media Pembelajaran PROTATIK Berbasis Website, Praktik Pelafalan, Mahasiswa. 
Pembelajaran bahasa pada dasarnya merupakan proses mempelajari bahasa. Mempelajari bahasa tentu tidak luput dari kesalahan. Khansir (2012) menyatakan bahwa semua orang yang belajar bahasa pasti tidak luput dari kesalahan dan kesalahan itu sumber inspirasi untuk menjadi benar. Studi mengenai kesalahan dan hubungannya dengan pengajaran bahasa perlu digalakkan sebab melalui kegiatan kajian kesalahan itu dapat diungkapkan berbagai hal berkaitan dengan kesalahan berbahasa yang dilakukan oleh siswa atau pembelajar.

Matakuliah Pronunciation Practice di Jurusan Pendidikan Bahasa Inggris merupakan matakuliah keterampilan terutama untuk keterampilan lisan, speaking dan listening. Tanpa penguasaan pronunciation yang memadai, mustahil seseorang dapat berbicara bahasa Inggris dengan baik. Kesalahan pronunciation atau pelafalan dapat menimbulkan salah paham. Untuk dapat dipahami orang lain, seseorang harus dapat mengucapkan bahasa Inggris dengan benar dan sebaliknya untuk dapat memahami bahasa Inggris orang lain, seseorang harus dapat menangkap dan memahami pronunciation orang lain.

Teknologi baru, terutama multimedia mempunyai peranan semakin penting dalam proses pembelajaran. Multimedia dapat mengubah situasi belajar dari learning with effort menjadi learning with fun. Proses pembelajaran yang menyenangkan, kreatif, tidak membosankan akan menjadi pilihan tepat bagi pendidik. Sistem pembelajaran yang selama ini dilakukan, yaitu sistem pembelajaran konvensional (faculty teaching), kental dengan suasana instruksional dan dirasa kurang sesuai dengan dinamika perkembangan ilmu pengetahuan dan teknologi yang demikian pesat. Sistem pembelajaran konvensional kurang fleksibel dalam mengakomodasi perkembangan materi kompetensi karena pendidik harus intensif menyesuaikan bahan ajar dengan perkembangan teknologi terbaru.

Saat ini, Indonesia memasuki era informasi, yaitu suatu era yang ditandai dengan makin banyaknya medium informasi, tersebarnya informasi yang makin meluas dan seketika, serta informasi dalam berbagai bentuk yang bervariasi tersaji dalam waktu yang cepat. Penyajian pesan pada era informasi ini akan selalu menggunakan media, baik elektronik maupun nonelektronik.

Berdasarkan uraian tesebut ditunjukkan bahwa kehadiran media telah memengaruhi seluruh aspek kehidupan, termasuk sistem pendidikan, meskipun dalam derajat yang berbeda-beda. Mahasiswa seharusnya memiliki keterampilan untuk membaca simbol bunyi yang digunakan dalam kamus-kamus sehingga ketika menemukan kata baru yang belum diketahui secara pasti ucapannya, mereka dapat mengeceknya melalui kamus. Namun kenyataannya tidak selalu demikian. Dalam berbagai kesempatan, bahkan dalam ujian skripsi, masih sering ditemukan mahasiswa yang salah mengucapkan kata-kata, bahkan kata-kata yang sering digunakan dalam komunikasi dan pembelajaran seharihari. Lebih parah lagi, jika mereka diminta mengecek ke dalam kamus, mereka tidak mampu membaca simbol bunyi dengan tepat. Fakta ini menunjukkan bahwa pembelajaran Pronunciation Practice belum berhasil secara maksimal. Hal itu akan berdampak buruk pada penguasaan bahasa Inggris secara keseluruhan, terutama pada bahasa lisan. Mahasiswa merupakan komponen utama dalam menentukan hasil belajar karena merekalah yang menjadi subjek pelaku kegiatan belajar. Mahasiswa dengan kemampuan awal cukup cenderung lebih mudah menerima dan memproses bahan ajar dan latihan dibanding mahasiswa dengan kemampuan awal rendah. Kemampuan awal juga ikut berpengaruh pada komponen pembelajaran yang lain, seperti pada penentuan silabus, tingkat kesulitan bahan ajar, teknik pengajaran, dan ragam latihan (Madya, 2000:9). Berdasarkan pengamatan selama ini, hasil belajar pronunciation practice yang baik hanya dapat dicapai oleh mahasiswa yang telah memiliki kemampuan awal cukup, 
sedangkan mahasiswa dengan kemampuan awal rendah kurang menampakkan hasil yang memuaskan. Peran dosen dalam pembelajaran Pronunciation Practice adalah sebagai pengelola kegiatan pembelajaran, sebagai motivator, fasilitator, dan model. Pengajar pronunciation practice harus mampu merancang kegiatan belajar mengajar yang layak, memilih materi yang sesuai, membantu mahasiswa dalam latihan, memonitor latihan dan kemajuan belajar mahasiswa, dan juga harus dapat menjadi contoh atau model bagaimana mengucapkan bahasa Inggris dengan baik dan benar. Menurut Nilsen (89:2002), hasil pengajaran atau pembelajaran dapat dilihat salah satunya melalui keefektifan pengajaran. Keefektifan (effectiveness) tersebut biasanya diukur dengan tingkat pencapaian atau perolehan belajar siswa. Paling tidak terdapat satu aspek penting dari empat aspek yang dapat dipakai untuk mendeskripsikan keefektifan pengajaran, yaitu kecermatan penguasaan perilaku yang dipelajari atau sering juga disebut dengan "tingkat kesalahan". Aspek lainnya adalah kecepatan unjuk kerja, tingkat alih belajar dan tingkat retensi dari apa yang dipelajari (Nilsen 90:2002).

Pengembangan fungsi audiovisual tatik berbasis web (Audiovisual Aids atau Teaching Aids) bertujuan memberikan pengalaman yang kongkret kepada mahasiswa dan berfungsi sebagai alat bantu agar dapat memperjelas melalui tampilan seperti tabel (agar lebih kongkret) materi yang disampaikan dosen karena kalau tidak menggunakan media, penjelasan dosen bersifat sangat abstrak. Saat ini teknologi komputer yang digunakan dalam pembelajaran bahasa dikenal dengan sebutan CALL (Computer Assisted Language Learning) Sharon (2011:457). Berbagai fasilitas atau layanan dapat disediakan melalui teknologi internet. World Wide Web bisa juga disebut web memungkinkan pengguna internet untuk dapat dengan mudah berpindah dari satu tempat ke tempat yang lain secara cepat dengan menggunakan Hiperlink (link). Melalui link ini pengguna internet dapat terhubung ke jenis sumber yang diinginkan (teks, video, suara, multimedia). Setiap organisasi, perusahaan atau pribadi dapat memperoleh informasi di World Wide Web. Untuk itu diperlukan suatu alamat (URL) spesifik yang disebut Website (Tomlinson, 2008:91).

Menurut Hetch (2007:77) belajar pronunciation memiliki dua tujuan, yaitu pertama untuk mencapai kemampuan memproduksi bunyi bahasa mendekati kualitas native speaker (penutur asli) dan yang kedua untuk bisa menghasilkan bahasa yang bisa dipahami dengan mudah dan benar, meskipun aksennya tidak begitu sempurna. Kelly (2000:82) mengatakan bahwa tujuan belajar pronunciation adalah kemampuan memproduksi bunyi bahasa kedua atau bahasa asing yang tidak menghambat jalannya komunikasi, baik dari sisi pembicara maupun pendengar. Berdasarkan pendapat ini, mahasiswa Jurusan Bahasa Inggris seharusnya mampu memproduksi bahasa lisan sebagaimana para penutur asli atau mendekati penutur asli. Mencapai hasil belajar pronunciation yang maksimal, yaitu bisa dipahami orang lain terlebih jika ingin mendekati bahasa penutur asli tidaklah mudah. Tujuan ini sering tidak dapat dicapai dengan baik sehingga masih sering ditemukan kesalahan pengucapan. Menurut Riswanto dan Haryanto (20012: 84), kesalahan pronunciation dapat diakibatkan oleh (1) bunyi bahasa tertentu tidak terdapat pada bahasa pertama/ibu sehingga pembelajar tidak terbiasa memproduksi bunyi bahasa tersebut dan cenderung menggantinya dengan bunyi bahasa yang mendekati, yang bisa dia produksi; (2) bunyi bahasa tersebut sebenarnya ada dalam bahasa pertama, tetapi tidak merupakan fonem tersendiri sehingga pembelajar tidak mampu menangkap bunyi bahasa tersebut sebagai fonem tersendiri yang dapat membedakan makna kata; dan (3) pembelajar mampu memproduksi bunyi bahasa dengan benar, tetapi belum mempelajari pola tekanan (stress pattern) dalam bahasa Inggris sehingga cenderung menggunakan intonasi bahasa pertama yang tidak sesuai dengan bahasa Inggris. Menurut Yulia dan Ouda (2004:23), 
kesalahan pronunciation disebabkan oleh perbedaan sistem tata bunyi bahasa target dan bahasa pertama. Yulia (2004:26) membandingkan antara bahasa Inggris dan bahasa Indonesia, dan menemukan adanya perbedaan-perbedaan. Beberapa bunyi konsonan bahasa Inggis tidak terdapat dalam bahasa Indonesia $\left.\left[\theta, \partial, \int, \mathrm{y}, \mathrm{v}\right], \mathrm{b}\right)$, beberapa konsonan bahasa Inggris ada dalam bahasa Indonesia, tetapi sifatnya berbeda, misalnya [d , t $\iint$ ). Dalam bahasa Indonesia s, dan z; s dan fbersifat alofonik, sedangkan dalam bahasa Inggris merupakan fonem tersendiri. Perbedaan ini juga terdapat dalam vokal maupun difthong [æ, i, a, 3, ei, u , e , au, u dan sebagainya]. Selain kesulitan yang disebabkan oleh sistem tata bunyi yang berbeda, ada juga sumber kesulitan yang lain, yaitu masalah ejaan. Dalam bahasa Indonesia, ejaan sangat dekat dengan ucapan sehingga mengucapkan bahasa Indonesia yang ditulis sangatlah mudah. Bahasa seperti ini juga disebut bahasa fonetis. Bahasa Inggris bukanlah bahasa fonetis karena hubungan antara ejaan dan ucapan sangat kompleks sehingga dapat menjadi sumber kesulitan tersendiri dalam belajar pronunciation bagi pembelajar bahasa Inggris sebagai bahasa asing yang mengenal bahasa Inggris berawal dari bahasa tulis (Yulia dan Ouda, 2004:30).

Dalam International Journal of Humanities and Social Science Vol. 2 No. 21; November 2012, Riswanto dan Haryanto (2012:82) menjelaskan bahwa pada dasarnya sistem bunyi dalam bahasa Indonesia serupa dengan sistem bunyi dalam bahasa Inggris. Meskipun demikian, ada sejumlah vokal dalam bahasa Inggris yang tidak muncul dalam bahasa Indonesia. Sejumlah konsonan bahasa Inggris juga tidak muncul dalam bahasa Indonesia. Dalam bahasa Indonesia juga dikenal adanya diftong, tetapi tidak memiliki kluster. Kluster dalam bahasa Indonesia hanya terjadi pada kata 'pinjaman', yaitu kata yang diserap dari bahasa lain. Dalam hal ini, kluster pada bahasa Indonesia diadopsi dari bahasa Inggris. Misalnya, strategi dari /strategy/, struktur dari /structure/, instrumen dari /instrument/, dan sebagainya. Dalam bahasa Inggris, tekanan sangat penting karena mempengaruhi makna suatu kata, sedangkan dalam bahasa Indonesia tekanan tidak begitu penting karena tidak memengaruhi makna suatu kata. Sejumlah bunyi dalam bahasa Inggris tidak ditemukan dalam bahasa Indonesia, dan bunyi-bunyi pada kedua bahasa yang memiliki tempat artikulasi yang sama sebenarnya memiliki cara artikulasi yang berbeda (Yulia, 2004:50).

Matakuliah Pronunciation Practice di Prodi Pendidikan Bahasa Inggris, FBS, UNINDRA PGRI Jakarta merupakan matakuliah yang didesain untuk mahasiswa tahun pertama, semester II dengan total 3 sks. Setelah menjalani matakuliah ini, diharapkan mahasiswa mampu berbicara dalam bahasa Inggris dengan received-pronunciation secara akurat dan alami. Proses perkuliahan yang selama ini dilaksanakan lebih berpusat pada dosen. Kegiatan mahasiswa di kelas terasa monoton dan tidak atraktif. Kegiatan pembelajaran hanya berpusat pada buku pegangan mahasiswa. Mahasiswa hanya diminta menirukan dosen secara individu setelah menemukan atau menulis cara pengucapan yang benar melalui kamus. Akibatnya, mahasiswa masih malu-malu untuk mengaplikasikan pengucapan (pronunciation practice) yang benar, seperti penutur asli dalam percakapan berbahasa Inggris. Pengucapan (pronunciation practice) yang benar memang akan terasa aneh dan terdengar lucu ketika dipraktikkan oleh mahasiswa yang enggan mengaplikasikan aspek pengucapan yang benar. Hal inilah yang menghambat peningkatan kemampuan mahasiswa dalam berbahasa Inggris.

Berdasarkan latar belakang penelitian yang telah diuraikan di atas, diharapkan pengembangan rancang bangun melalui audiovisual PROTATIK (program tabel fonetik) berbasis website dapat menjadi solusi untuk media pembelajaran Pronunciation Practice yang efektif di perguruan tinggi sehingga memberikan hasil yang baik terhadap kemampuan pengucapan mahasiswa. 


\section{METODE}

Untuk menghasilkan produk media pembelajaran yang layak pakai dan sesuai dengan kebutuhan, perlu ditempuh suatu pendekatan penelitian dan pengembangan. Penelitian dan pengembangan merupakan metode untuk mengembangkan dan menguji suatu produk. Menurut Sadiman (2005: 64), penelitian dan pembuatan/pengembangan dapat digunakan untuk mengembangkan buku, modul, media pembelajaran, instrumen evaluasi, model-model kurikulum, pembelajaran, evaluasi dan lain-lain. Menurut Sadiman (2005:68) secara garis besar ada tiga langkah penelitian dan pengembangan, yaitu (1) studi pendahuluan dengan mengkaji teori dan mengamati produk atau kegiatan yang ada, (2) melakukan pengembangan produk atau program kegiatan baru, dan (3) menguji atau memvalidasi produk atau program kegiatan yang baru. Langkah pertama telah dilakukan melalui studi pendahuluan dengan cara mengkaji teori tentang pembuatan media dan isi media yang akan dikembangkan yang tertuang dalam kajian pustaka. Untuk pengembangan media pembelajaran Pronunciation Practice ditempuh dengan langkah (1) melakukan analisis kebutuhan; (2) mengembangkan silabus, materi pembelajaran, dan bahan latihan; (3) pembuatan media pembelajaran dalam bentuk rancang bangun PROTATIK berbasis website; dan (4) melakukan ujicoba serta perbaikan media pembelajaran.

Data penelitian diambil dari dosen-dosen dan mahasiswa kelas Pronunciation Practice dari Universitas Indraprasta PGRI Jakarta. Data berupa data kualitatif, yaitu pendapat dan saran baik dari dosen maupun mahasiswa yang dikumpulkan dengan cara diskusi melalui rekan sejawat, observasi atau pengamatan kelas, dan kuesioner.

Adapun instrumen dalam penelitian ini meliputi rekaman pelaksanaan dan kuesioner. Selanjutnya, data diskusi melalui rekan sejawat dan mahasiswa, observasi atau pengamatan kelas, serta kuesioner dianalisis secara kualitatif deskriptif dan langsung diterapkan untuk pengembangan dan perbaikan media pembelajaran dalam matakuliah Pronunciation Practice.

\section{PEMBAHASAN}

Hasil penelitian ini berupa rancang bangun audiovisual PROTATIK (program tabel fonetik) media pembelajaran Pronunciation Practice berbasis website berbentuk aplikasi yang berisi tampilan tabel pengucapan bunyi konsonan dan vokal dalam bahasa Inggris yang dapat didengar sekaligus dilengkapi tombol-tombol latihan untuk mahasiswa berlatih serta tombol ikon suara nonpenutur asli untuk materi praktik pelafalannya (diwaliki dosen pengampu Pronunciation Practice yang direkomendasikan) karena penyajiannya yang interaktif dan jelas. Alasan pemilihan nonpenutur asli untuk mengisi latihan praktiknya karena mereka yang nonpenutur asli biasanya berbicara dengan lebih teratur dan hati-hati, khas seseorang yang berbicara bahasa kedua atau ketiga. Mengembangkan rancang bangun audiovisual PROTATIK media pembelajaran Pronunciation Practice ini dilakukan dengan langkah-langkah (1) analisis kebutuhan, (2) pengembangan silabus dan penyusunan materi serta bahan latihan, (3) pembuatan media, dan (4) uji coba dan perbaikan media.

Untuk mengetahui dengan pasti media pembelajaran yang dibutuhkan dalam pembelajaran Pronunciation Practice di Prodi Pendidikan Bahasa Inggris FBS Universitas Indraprasta PGRI, tim peneliti melakukan refleksi tentang pembelajaran Pronunciation Practice yang telah berlangsung selama ini. Hasil refleksi ini dibahas dalam tim yang terdiri dari dosen-dosen pengampu Pronunciation Practice untuk mendapatkan tambahan dan validasi data tentang permasalahan yang ada dalam perkuliahan Pronunciation Practice serta media seperti apa yang diperlukan untuk 
mengatasi permasalahan yang ada. Pengajaran Pronunciation Practice selama ini terasa belum berhasil dengan maksimal yang ditandai dengan berbagai hal. Hasil belajar mahasiswa kurang begitu memuaskan saat menempuh ujian. Mahasiswa dapat menirukan apa yang diucapkan oleh dosen saat pengajaran, namun mereka cepat melupakannya. Tim peneliti menyadari bahwa mereka membutuhkan model pronunciation practice yang mutakhir serta dapat didengar dan ditirukan kapanpun mereka butuhkan yang tidak terbatas oleh ruang dan waktu. Selama ini model pronunciation practice manual diberikan langsung oleh dosen saat mengajar di dalam kelas tanpa disertai dengan rekaman. Hal tersebut cepat dilupakan oleh mahasiswa serta cukup melelahkan bagi dosen pengampu. Dosen harus berteriak mengulang-ulang katakata, frasa, kalimat-kalimat yang sama dari kelas ke kelas. Untuk mengatasi masalah ini, modul perkuliahan yang baik sangat diperlukan. Bahan ajar perkuliahan Pronunciation Practice yang ada di Jurusan Bahasa Inggris selama ini berupa buku pegangan perkuliahan yang berjudul Teaching to Mastery: Pronunciation Practice: A Pronunciation Teaching-Learning Tool (Purwanto Andri, Retnomurti Ayu \& Mutiara Dewi, 2016). Modul manual/Unindra handbook ini memuat semua materi perkuliahan disertai dengan bahan latihan yang cukup memadai. Sayangnya modul ini tidak disertai dengan rekaman model ucapan atau practice yang sangat diperlukan baik oleh dosen maupun mahasiswa. Oleh karena itu, modul perkuliahan yang disertai dengan rekaman model ucapan yang baik sangat diperlukan. Membuatkan bahan rekaman untuk modul yang sudah ada sangat mungkin dilakukan untuk meningkatkan kualitas pembelajaran Pronunciation Practice sehingga media pengajaran tidak hanya berupa modul, tetapi juga tabel bunyi dalam Bahasa Inggris serta Protatik rekaman bahan practice atau latihan yang akan memudahkan kerja dosen dalam memberikan model ucapan yang dapat digunakan oleh mahasiswa belajar di rumah. Namun jika mengingat kemajuan IT saat ini, pengajaran dengan modul manual barang kali sudah tidak begitu menarik lagi. Saatnya kita mengembangkan modul manual yang sudah ada ini menjadi modul berbasis teknologi tepat guna yg mutakhir berupa Protatik dalam bentuk media pengajaran Pronunciation Practice yang lebih menarik dengan memanfaatan teknologi berbasis website. Hasil refleksi tentang pengajaran Pronunciation Practice di jurusan Pendidikan Bahasa Inggris ini dibawa ke forum diskusi dosen pengajar Pronunciation Practice untuk mendapatkan tanggapan, tambahan, dan kejelasan mengenai media yang sebenarnya diperlukan. Berdasarkan hasil diskusi, para dosen umumnya menghadapi permasalahan yang sama dalam pengajaran Pronunciation Practice sehingga semua sepakat bahwa yang diperlukan adalah materi perkuliahan yang telah tersusun secara sistematis disertai dengan bahan-bahan latihan memadai, bahan rekaman, latihan atau practice yang dapat dipakai dalam pengajaran Pronunciation Practice di kelas. Seorang dosen berpendapat bahwa bentuk media tidak harus canggih bahkan cukup modul dan kaset rekaman. Namun ada juga yang berpendapat bahwa media sebaiknya mengikuti perkembangan teknologi sehingga tidak ada salahnya media tersebut berbasis komputer sehingga kemudahan dan fasilitas yang ada dalam komputer dapat dimanfaatkan untuk mengoptimalkan proses pembelajaran maupun hasilnya. Bahan-bahan yang harus tercakup dalam media ini meliputi tabel bunyi bahasa Inggris, sedangkan materi latihan atau practice harus meliputi kata-kata lepas, kelompok kata, teks, dan kalimat berbagai bentuk, dialog, maupun paragraf.

Silabus atau Satuan Acara Perkuliahan (SAP) disusun berdasarkan deskripsi matakuliah Pronunciation Practice kurikulum Pendidikan Bahasa Inggris FBS Universitas Indraprasta PGRI 2015/2016, tujuan pembelajaran dan cakupan materi pengajaran Pronunciation Practice dari UNINDRA Handbook (2016) dan Hancock (2003): English Pronunciation in Use; Self Study and Classroom Use serta hasil diskusi 
rekan sejawat pengampu Pronunciation Practice pada tahap analisis kebutuhan. Bahan practice atau latihan dikembangkan sesuai dengan materi perkuliahan ditambah dengan latihan lain untuk pengembangan keterampilan yang diperlukan meliputi pengucapan kata-kata lepas, kelompok kata, teks, kalimat, paragraf dan dialog. Silabus perkuliahan ini mencakup lima komponen, yaitu (1) topik pembelajaran, (2) tujuan pembelajaran, (3) materi pembelajaran, dan (4) practice atau latihan.

\begin{tabular}{|c|c|c|c|}
\hline Topik/Pokok Bahasan & Tujuan & Deskripsi Materi & Practice atau Latihan \\
\hline 1. Introduction & $\begin{array}{l}\text { Mahasiswa } \\
\text { Memiliki gambaran } \\
\text { secara menyeluruh } \\
\text { isi perkuliahan } \\
\text { Pronunciation } \\
\text { Practice }\end{array}$ & $\begin{array}{l}\text { Definition of } \\
\text { Pronunciation } \\
\text { Table of English } \\
\text { sounds } \\
\text { Letters and sounds }\end{array}$ & $\begin{array}{l}\text { Kata-kata lepas (regular, } \\
\text { irregular verbs, plural forms) } \\
\text { frase, teks, kalimat berbagai } \\
\text { bentuk, paragraf, dan dialog }\end{array}$ \\
\hline $\begin{array}{l}\text { 2. Vowels } \\
\text { 1. /i/ \& /i:/ } \\
\text { 2. / / \& /u:/ } \\
\text { 3. /a:/ \& / / } \\
\text { 4. / / \& / :/ } \\
\text { 5. /e/ \& /æ/ } \\
\text { 6. /3:/ \& / / } \\
\text { 7. /i / \& /e / } \\
\text { 8. /ei/, /ai/ \& / i/ } \\
\text { 9. / / \& /a / }\end{array}$ & $\begin{array}{l}\text { 1.Mahasiswa dapat } \\
\text { menyebutkan } \\
\text { bunyi-bunyi Vowel } \\
\text { Bahasa Inggris } \\
\text { 2.Mahasiswa dapat } \\
\text { memproduksi } \\
\text { bunyi-bunyi vowel } \\
\text { Bahasa Inggris }\end{array}$ & The Vowel sounds & $\begin{array}{l}\text { Kata-kata lepas semua bunyi } \\
\text { vowel Bhs. Inggris dari bunyi- } \\
\text { bunyi vowel yang sulit bagi } \\
\text { mahasiswa Indonesia }\end{array}$ \\
\hline $\begin{array}{l}\text { 3. Consonants: } \\
\text { 10./p/ \& /b/ } \\
11 . / \mathrm{t} / \& / \mathrm{d} / \\
12 . / \mathrm{k} / \& / \mathrm{g} \\
13 . / \mathrm{v} / \& / \mathrm{f} / \\
14 . / / \& / ð / \\
15 . / \mathrm{s} / \& / \mathrm{z} / \\
16 . / / \& / / \\
17 . / \mathrm{t} / \& / \mathrm{d} / \\
18 . / \mathrm{m} /, / \mathrm{h} / \& / \mathrm{h} / \\
19 . / \mathrm{h} /, / \mathrm{l} / \& / \mathrm{r} / \\
20 . / \mathrm{w} / \text { and /j/ }\end{array}$ & $\begin{array}{l}\text { 1.Mahasiswa } \\
\text { memiliki gambaran } \\
\text { tentang Consonant } \\
\text { dalam bunyi } \\
\text { Bahasa Inggris } \\
\text { 2.Mahasiswa dapat } \\
\text { mengucapkan } \\
\text { contoh bunyi-bunyi } \\
\text { Consonant dalam } \\
\text { kata-kata dengan } \\
\text { benar tanpa melihat } \\
\text { kamus }\end{array}$ & $\begin{array}{l}\text { The consonant sound } \\
\text { serta ringkasan dalam } \\
\text { bentuk tabel bunyi } \\
\text { Consonant kata-kata } \\
\text { dengan ucapannya }\end{array}$ & $\begin{array}{l}\text { Kata-kata lepas dengan } \\
\text { kelompok bunyi Consonant }\end{array}$ \\
\hline $\begin{array}{l}\text { 4. -Syllables } \\
\text {-Words }\end{array}$ & $\begin{array}{l}\text { 1.Mahasiswa dapat } \\
\text { membedakan } \\
\text { perbedaan suku } \\
\text { kata dan kata } \\
\text { 2.Mahasiswa dapat } \\
\text { mengucapkan suku } \\
\text { kata dan kata } \\
\text { dengan tekanan } \\
\text { yang berbeda } \\
\text { 3.Mahasiswa dapat } \\
\text { menentukan berapa } \\
\text { suku kata dari tiap } \\
\text { contoh kata dalam } \\
\text { frase maupun } \\
\text { kalimat dapat } \\
\text { 4.Mahasiswa dapat } \\
\text { mengucapkan suku } \\
\text { kata dan kata dan } \\
\text { kata baik frase } \\
\text { maupun kalimat }\end{array}$ & $\begin{array}{l}\text { Introduction to } \\
\text { syllables } \\
\text { Consonants at the } \\
\text { start of syllables } \\
\text { Consonants at the end } \\
\text { of syllables } \\
\text { Syllables: plural and } \\
\text { other -s endings } \\
\text { Syllables: adding past } \\
\text { tense endings } \\
\text { Introduction to word } \\
\text { stress } \\
\text { Stress in two-syllable } \\
\text { words } \\
\text { Stress in compound } \\
\text { words } \\
\text { Stress in longer words } \\
1 \\
\text { Stress in longer words } \\
2\end{array}$ & $\begin{array}{l}\text { Kata-kata lepas: verbs and } \\
\text { Nouns, kata-kata dengan } \\
\text { konsonan diawal suku kata, } \\
\text { diakhir suku kata, suku kata } \\
\text { jamak, akhiran -s, akhiran past } \\
\text { tense, penekanan kata kata } \\
\text { jamak, dan kalimat majemuk } \\
\text { bertingkat serta setara }\end{array}$ \\
\hline
\end{tabular}


Retnomurti, Octavita, Pengembangan Protatik (Program Tabel Fonetik) Berbasis Website | 139

\begin{tabular}{|c|c|c|c|}
\hline Topik/Pokok Bahasan & Tujuan & Deskripsi Materi & Practice atau Latihan \\
\hline $\begin{array}{l}\text { 5.Sentences (part I) } \\
\text { Sentences (part II) } \\
\text { Sentences (part III) }\end{array}$ & $\begin{array}{l}\text { dengan benar } \\
\text { Mahasiswa dapat } \\
\text { mengucapkan } \\
\text { phrases, sentences, } \\
\text { passages, } \\
\text { dialogues dengan } \\
\text { benar dan lancar }\end{array}$ & $\begin{array}{l}\text { Introduction to } \\
\text { sentence stress } \\
\text { Sentences with all the } \\
\text { words stressed } \\
\text { Unstressed words } \\
\text { Pronouns and } \\
\text { contractions } \\
\text { Pronouncing the verb } \\
\text { be } \\
\text { Auxiliary verbs } \\
\text { Pronouncing short } \\
\text { words (a, of, or) } \\
\text { Joining words } 1 \\
\text { Joining words } 2 \\
\text { Joining words } 3\end{array}$ & $\begin{array}{l}\text { Contoh-contoh kalimat yang } \\
\text { mengandung unsur } \\
\text { stress/unstress dalam kalimat, } \\
\text { pronominal, kata kerja auxiliary, } \\
\text { serta kata sandang/article }\end{array}$ \\
\hline
\end{tabular}

Tabel 1: Silabus/SAP Pronunciation Practice

Materi perkuliahan dan bahan practice atau latihan dari model penutur/nonnative speaker yang telah tersusun kemudian dituangkan dalam bentuk aplikasi (audiovisual Protatik berbasis website). Aplikasi ini dibuat dengan menggunakan program PHP, Java Script, Jquery, dan CSS. Serta Tools yang digunakan adalah Macromedia Dreamweaver dan Adobe Photoshop. Pembuatan aplikasi ini dibagi menjadi beberapa tahapan, yaitu analisis, desain program, uji coba, dan evaluasi. Materi yang telah dikembangkan pada langkah sebelumnya dianalisis, didesain, dan diketik pada program Microsoft Word karena jika materi diketik langsung pada program PHP, Java Script, Jquery, dan CSS akan terlalu panjang dan sangat sulit untuk diedit. Setelah semua materi selesai dianalisis, langkah selanjutnya adalah menyalin materi ke dalam program PHP, Java Script, Jquery, dan CSS. Setelah itu, pada setiap halaman file PHP disisipkan perintah yang dikehendaki yang antara lain menuju dan kembali ke halaman berikutnya ataupun sebelumnya, memutar dan menghentikan suara, menuju file lain, dan memunculkan tabel simbol bunyi. Proses selanjutnya adalah perekaman suara nonnative speaker. Suara hasil rekaman digunakan untuk mengisi tombol icon practice yang terdapat dalam aplikasi Protatik ini. Suara tersebut direkam dari model penutur/suara dosen Jurusan Pendidikan Bahasa Inggris yang lulus seleksi. Suara direkam dengan menggunakan program Macromedia Dreamweaver dan Adobe Photoshop melalui fasilitas Windows Media Player dari Microsoft. Setelah suara direkam, file suara kemudian disimpan dalam format WAV, MP3 kemudian diedit untuk disesuaikan tinggi rendah, volume, dan menghilangkan noise yang ada. File suara yang telah diedit kemudian dihubungkan dengan file PHP yang telah disisipi perintah. Setelah tiap halaman dihubungkan dengan file suara, proses selanjutnya adalah uji coba lalu pengecekan tiap halaman. Proses ini dilakukan untuk melihat kesesuaian perintah yang diberikan dengan hasil yang dikehendaki. Uji coba ini sangatlah diperlukan sebab setelah dicek, ternyata masih banyak perintah yang tidak berjalan maupun tidak sesuai dengan yang dikehendaki. Setelah file diuji coba, kemudian dilakukan perbaikan file oleh tim peneliti sendiri. Tim peneliti menggunakan suara nonnative speaker untuk proses belajar mengajar di kelas sesuai kesepakatan antarrekan pengampu Pronunciation Practice agar tercapainya target kegiatan belajar mengajar di kelas. Untuk latihan-latihan praktik pengucapannya menggunakan suara nonnative speaker dari rekan sejawat sendiri yang telah lulus seleksi. Menurut Jenkins seorang profesor bahasa Inggris global di University of Southampton Inggris "Penutur bahasa Inggris asli/native speaker biasanya monolingual dan tidak terlalu pintar dalam menyesuaikan 
diri dengan variasi berbahasa,". Dia menambahkan bahwa nonpenutur asli/nonnative speaker berbicara dengan lebih teratur dan hati-hati, khas seseorang yang berbicara bahasa kedua atau ketiga. Di lain sisi, para penutur bahasa Inggris/native speaker, sering kali berbicara terlalu cepat untuk diikuti oleh yang lain, menggunakan lelucon, bahasa slang dan merujuk pada hal-hal yang spesifik kebudayaan mereka sendiri. Nonpenutur asli biasanya menggunakan kosa kata yang lebih terbatas dan ungkapan-ungkapan yang lebih sederhana, tanpa bahasa yang berbunga-bunga atau bahasa slang. Karena itulah, mereka saling memahami melalui mimik wajah. Tampilan aplikasi protatik dapat dilihat pada gambar berikut.

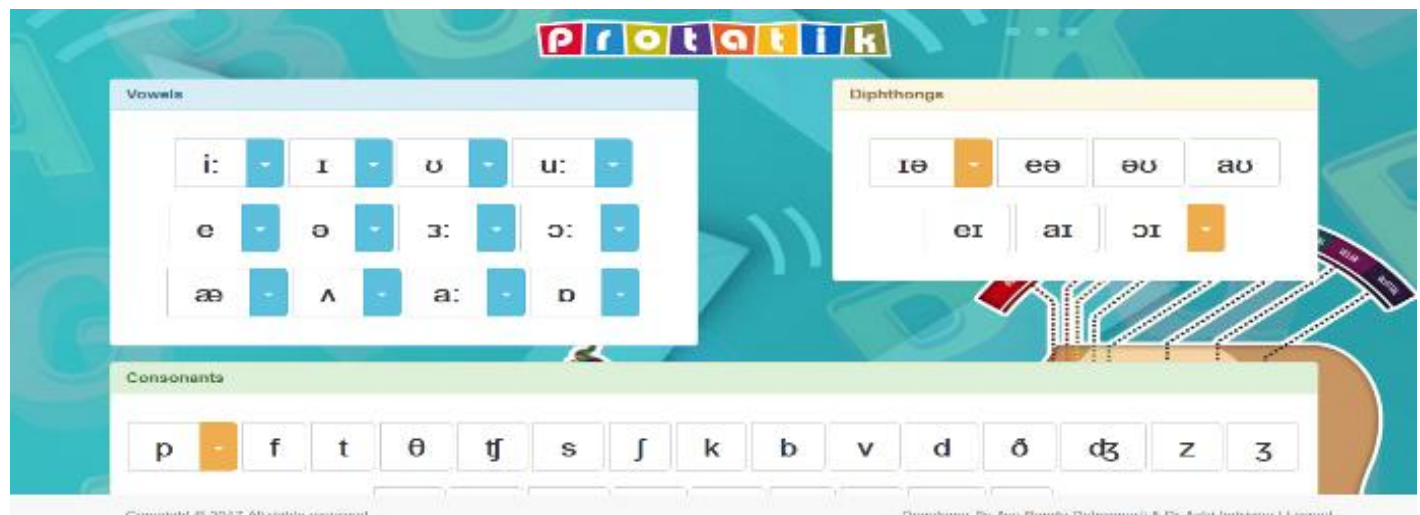

Gambar 1. Tampilan aplikasi media pembelajaran Protatik berbasis website

Media pembelajaran Protatik berbasis website yang telah dikembangkan ini kemudian diujicobakan untuk pembelajaran di kelas. Uji coba ini dilakukan di kelas matakuliah Pronunciation Practice untuk mengetahui lebih detail beberapa bagian yang mungkin masih belum terdeteksi oleh tim peneliti. Proses ini juga sangat diperlukan untuk mendapatkan saran yang membangun dari mahasiswa. Uji coba ini melibatkan kelas Pronunciation Practice (R2A dan R2B). Pada akhir pembelajaran mereka diminta memberikan komentar pada media pembelajaran Protatik yang baru saja mereka gunakan. Komentar mereka meliputi tiga hal, yaitu kelebihan dan kekurangan media tersebut serta saran perbaikannya.

\begin{tabular}{|c|c|c|}
\hline No & Komentar & $\begin{array}{c}\text { Frekuensi banyaknya } \\
\text { mahasiswa }\end{array}$ \\
\hline \multirow[t]{11}{*}{1} & Kelebihan media: & \\
\hline & 1. Sangat bermanfaat bagi mahasiswa dalam belajar & 17 \\
\hline & Pronunciation Practice di kelas & \\
\hline & 2. Mudah dioperasikan penggunaannya & 11 \\
\hline & 3. Simbol bunyi bahasa Inggris cukup jelas & 6 \\
\hline & 4. Berisi latihan dan praktik yang cukup lengkap & 5 \\
\hline & 5. Membantu mahasiswa dalam belajar mandiri & 2 \\
\hline & $\begin{array}{l}\text { 6.Fleksibel, mahasiswa dapat memilih sendiri bahan/latihan } \\
\text { yang mau dipelajari }\end{array}$ & 2 \\
\hline & 7. Menarik desainnya & 2 \\
\hline & $\begin{array}{l}\text { 8. Model penutur dosennya/non-native speaker terdengar } \\
\text { jelas dibandingkan native speaker/penutur aslinya }\end{array}$ & 1 \\
\hline & 9. suara rekaman PROTATIK jelas & 1 \\
\hline \multirow[t]{3}{*}{2} & Kelemahan media & \\
\hline & 1 Kemasan kurang menarik & 5 \\
\hline & $\begin{array}{l}2 \text { Tidak dapat digunakan jika mahasiswa tidak punya } \\
\text { komputer }\end{array}$ & 2 \\
\hline
\end{tabular}




\begin{tabular}{lc}
\hline No & \multicolumn{1}{c}{ Komentar } \\
\hline $\begin{array}{l}\text { 3. Kurang praktis, karena mahasiswa harus ngeklik banyak } \\
\text { ikon } \\
\text { 4. Kurang latihan dalam bentuk syair atau teks-teks lagu } \\
\text { guna mengecek kosakata kita apakah sudah sesuai dengan } \\
\text { pelafalan atau belum }\end{array}$ & $\begin{array}{c}\text { Frekuensi banyaknya } \\
\text { mahasiswa }\end{array}$ \\
Saran perbaikan & 1 \\
1. Perbaiki kesalahan yang ada & 4 \\
2. Tambah animasi & \\
3. Agar dibuat lebih pelan/ lambat & 4 \\
4. Tambahkan musik di tengah program & 3 \\
5. Tambahkan contoh-contoh lebih banyak & 2 \\
6. Supaya warna dibuat lebih lembut & 1 \\
7.Supaya warna dibuat lebih cerah & 1 \\
10. Agar aplikasi dalam bentuk aplikasi berbasis web & 1 \\
PROTATIK ini diberikan kepada mahasiswa secara gratis & 1 \\
\end{tabular}

Tabel 2: Komentar mahasiswa pada uji coba PROTATIK di tahun pertama

\section{PENUTUP}

\section{Simpulan}

Setelah mengembangkan media pembelajaran berbasis website Protatik dan melakukan ujicoba di tahun pertama penggunaan media tersebut dalam pembelajaran Pronunciation Practice di kelas, tim peneliti dapat menyimpulkan (1) proses pengembangan media pembelajaran adalah bidang antardisiplin. Diperlukan kerjasama yang sinergis antara dosen yang menguasai bidang ilmu dan pengajarannya dan orang yang ahli/programmer di bidang teknik pembuatan media, yang menguasai programprogram komputer atau teknologi informasi dan juga memahami bidang pengajaran yang akan dikembangkan, (2) nonnative speaker sebagai pengisi suara juga harus memiliki suara yang jelas dan bagus dan dituntut memiliki kemampuan mengucapkan bahasa Inggris mendekati sempurna, (3) isi dari media pengajaran berbasis website Protatik yang dikembangkan ini diambil dari sumber-sumber yang sudah ada, baik sumber yang berupa tulisan maupun rekaman suara. Sumber-sumber tertulis berasal dari Mark Hancock, sedangkan, sumber berupa rekaman suara non/native speaker dari dosen pengampu Pronunciation Practice. Materi praktik berasal dari Paulette Wainless Dale, Ph. D dan Lillian Poms, M.Ed (English Pronunciation for Students). Sumber-sumber tersebut milik orang lain, dengan demikian media pengajaran Protatik yang dikembangkan ini tidak boleh diperjual-belikan baik kepada mahasiswa maupun institusi peneliti bernaung, sebelum didaftarkan pada Hak Atas Kekayaan Intelektual (HAKI) secara resmi. Media Protatik berbasis website sementara ini hanya dipakai untuk kalangan terbatas, yaitu untuk pengajaran Pronunciation Practice di Jurusan Pendidikan Bahasa Inggris FBS Universitas Indraprasta PGRI Jakarta di tahun pertama.

\section{Saran}

Media berupa alat bantu ajar yang telah berhasil dikembangkan ini berupa aplikasi Program Tabel Fonetik/Protatik berbasis website. Untuk dapat menggunakan media ini dalam pembelajaran diperlukan fasilitas tertentu, misalnya laboratorium bahasa, laboratorium komputer, atau ruang kelas yang dilengkapi dengan komputer, LCD, dan speaker. Bagi mahasiswa yang menggunakan Flash Disk atau jaringan internet untuk belajar mandiri di rumah, minimal mereka harus memiliki computer/laptop/notebook di 
rumahnya. Media ini cukup efektif untuk memfasilitasi dosen pengampu Pronunciation Practice maupun mahasiswa dalam proses belajar mengajar. Dosen di kelas mendapatkan kemudahan dalam menyampaikan materi dan memberikan model ucapan yang baik dan benar, sehingga mahasiswa dapat lebih memahami isi materi, dapat menikmati proses belajar mengajar di kelas dengan senang dan tertarik untuk belajar.

\section{DAFTAR RUJUKAN}

Hancock, M. 2003. English Pronunciation in Use; Self Study and Classroom Use. Cambridge: Cambridge University Press.

Hetch, B.F. 2007. The Acquisition of Second Language Phonology: Interaction of Transfer and Development Factors, Cambridge, Newbury House Publisher.

Khansir, A. A. 2012. Error Analysis and Second Language Acquisition, Theory and Practice in Language Studies, 2(5), 1027, 2012.

Kelly, Gerald. 2000. How to Teach Pronunciation. England: Longman Pearson Education Limited.

Madya, S. 2000. Learning English Pronunciation Systematically, Faculty of Languages and Arts, State University of Yogyakarta.

Nilsen, Don, L F. and Alleen, P. N. 2002. Pronunciation Contrast in English. Waveland Illinois USA: Pearson Education Inc.

Purwanto, A., Retnomurti, A. and Mutiara, Dewi. 2016. Teaching to MasterPronunciation Practice-A Pronunciation Teaching Learning Tool-An Effective Pronunciation-Teaching Learning Strategy, UNINDRA English Pronunciation Handbook.

Riswanto and Haryanto, E. 2012. "Improving Students' Pronunciation through Communicative Drilling Technique at Senior High School (SMA) 07 South Bengkulu, Indonesia", International Journal of Humanities and Social Science, Volume 2 No. 21, November 2012.

Sadiman, A. 2005. Media Pendidikan. Jakarta. PT Raja Grafindo Perkasa.

Sharon, E. S. 2011. Teknologi Pembelajaran dan Media untuk Belajar. Jakarta.

Tomlinson, Brian. 2008. Materials Development in Language Teaching. United Kingdom: Cambridge University Press.

Yulia, M.F. and Ouda, T. E. 2004. "Pronunciation Problems of Indonesians EFL Teachers", The Proceeding of the $9^{\text {th }}$ English in Southeast Asia Conference USD. Yogyakarta. 